\title{
GOLPE DE MANO DE LOS CABALLEROS SANJUANISTAS CONTRA LOS CASTILLOS DE PATRAS Y LEPANTO (1603)*
}

\author{
José M. Floristán \\ Universidad Complutense de Madrid \\ floris@filol.ucm.es
}

\section{RESUMEN}

Edición comentada de la relación de la toma de los castillos de Patras y Lepanto (Río, Antírrio) por los caballeros de la Orden de San Juan de Malta el 20 de abril de 1603. Fue enviada por el gran maestre Alof de Wignacourt a Felipe III. Se añade un capítulo prosopográfico

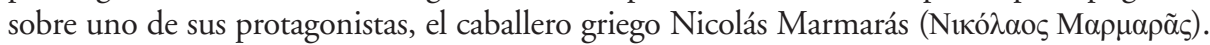
Palabras Clave: Castillos de Patras y Lepanto, Orden de Malta, Nicolás Marmarás.

\section{RAID OF THE KNIGHTS OF THE ORDER OF SAINT JOHN OF MALTA AGAINST THE CASTLES OF PATRAS AND LEPANTO (1603)}

\section{ABSTRACT}

Edition, with a commentary, of the report of the raid that the knights of the Order of Saint John of Malta made on the castles of Patras and Lepanto (Rio, Antirrio) in April 20th, 1603. The report was sent by the grand master Alof de Wignacourt to Philipp III of Spain. Prosopographical news about one of the main heroes of the raid, the Greek knight Nicholas Marmaras (Nıкó $\alpha \alpha_{\circ}$ M $\left.\alpha \rho \mu \rho \tilde{\alpha} \varsigma\right)$, is added.

KeYwords: Castles of Patras and Lepanto, Order of Malta, Nicholas Marmaras.

\section{EL CONTEXTO HISTÓRICO}

La Larga Guerra por el Danubio entre el Imperio Germánico y la Sublime Puerta en los años finales del siglo XVI e iniciales del XVII (1593-1606) reavivó las ansias de rebelión de las comunidades cristianas de los Balcanes contra el dominio otomano. La situación interna de Turquía era, en apariencia, más propicia para ello que cuarenta años antes: la indolencia de los sultanes que sucedieron a Selim II, muerto en 1574; el desgaste militar de Turquía por las constantes guerras en los frentes oriental (contra Persia) y occidental (contra la cristiandad); el deterioro económico provocado por la inflación, y las revueltas internas de Anatolia hicieron que Turquía llegara a finales del siglo XVI en una situación de debilidad alejada del esplendor del reina- 
do de Solimán el Magnífico (1520-1566). Distintos grupos de interior del Imperio -eslavos, albaneses y griegos-, en especial de la fachada adriatico-jónica, consideraron llegado el momento de intentar un levantamiento contra sus dominadores con ayuda de algún príncipe o república occidental, en especial, del Imperio y de la Monarquía Española, pero también de Estados italianos como Saboya, Mantua, Parma o Florencia (Bartl, 1974). Así, entre 1595 y 1597 Atanasio I de Acrida estuvo al frente de la revuelta de los habitantes de Chimarra (Himarë), en el sur de Albania, y pidió ayuda militar a las autoridades españolas de Nápoles. Ante la falta de respuesta pasó a Nápoles, en donde permaneció unos meses. En junio de 1598 viajó a la corte de Praga del emperador Rodolfo II, que le dio una ayuda económica y una carta de recomendación para su sobrino y primo Felipe III (Floristán, 2017: 148-159). La misma ruta de Praga a Madrid siguieron unos meses después los cuatro embajadores griegos que, llegados a la corte en fecha incierta del año 1600, probablemente después del verano, se presentaron como emisarios de las provincias de Epiro, Tesalia,

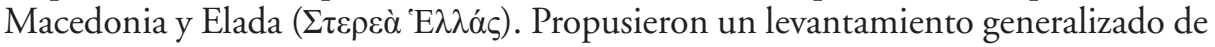
sus provincias que debía empezar por la ciudad de Prevesa (Прє́ $\beta \varepsilon \zeta \alpha$ ), que se comprometían a entregar a las fuerzas españolas que acudieran a socorrerlos (Floristán, 1988: 3-19; 1993). Los embajadores quisieron enmarcar el levantamiento en el ámbito de la guerra danubiana, por lo que propusieron que se invitara a Mihai Viteazul, vaivoda de Valaquia, a tomar los pasos al sur de Belgrado para impedir el retorno a Grecia de los soldados turcos estacionados en Hungría y Transilvania. Pedían, además, que Jorge Basta, estradiote albanés natural de Roccaforzata (Apulia), que había hecho carrera militar en Flandes y en 1597 había sido enviado a luchar en Transilvania contra Segismundo Báthory, se pusiera al frente de su levantamiento.

Aunque las circunstancias políticas y militares eran, quizás, más favorables a una empresa antiturca de envergadura, los deseos de los griegos chocaban con la realidad histórica. Los grandes enfrentamientos hispano-otomanos (Los Gelves 1560; Malta 1565; Lepanto 1571 y Túnez y La Goleta 1573-1574) quedaban atrás en el tiempo. La tregua firmada por Giovanni Margliani en 1578 y renovada en los años siguientes había traído una cierta paz al Mediterráneo (Floristán, 1998). La rebelión de Flandes, la guerra contra Inglaterra, la intervención en las guerras de Francia y la incorporación de Portugal habían desplazado el centro de atención de la Monarquía al Atlántico, lo que contribuyó al afianzamiento de esa paz. En los años finales del s. XVI e iniciales del s. XVII las grandes expediciones navales dejaron paso a una lucha pirática de asaltos y saqueos de puntos costeros del Imperio Otomano protagonizados por las galeras de los reinos de Nápoles y Sicilia y de las Órdenes militares de Malta y de San Esteban de Florencia: Patras en 1595, Quíos en 1599, la fortaleza de Pasabás (Maina) en 1601, los castillos de Lepanto y Patras en 1603, Cos en 1604,

* Abreviaturas empleadas: AGS: Archivo General de Simancas; E1694: Estado, legajo 1694; SP994: Secretarías Provinciales, legajo 994; f.: folio; s.f.: sin foliar. 
Psili (Anatolia) y Prevesa en 1605, Durazzo en 1606, Famagusta en 1607, la expedición de Antonio Sherley al Egeo y el desembarco en la isla de Escíatos en 1610, etc. Por lo general, los rebeldes balcánicos no veían con buenos ojos estas acciones. La inactividad bélica de las dos últimas décadas del s. XVI había provocado una relajación de las medidas defensivas de los turcos, a los que estas acciones militares ponían sobre aviso. En un memorial de 1606 los rebeldes de las provincias del Epiro-Tesalia dicen que las tomas de Lepanto y Patras por las galeras de Malta en 1603 y de Prevesa por las de Florencia en 1605 habían servido para despertar a los turcos y desbaratar su plan de revuelta:

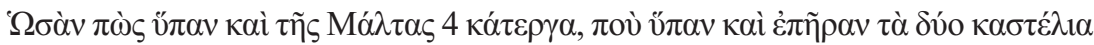

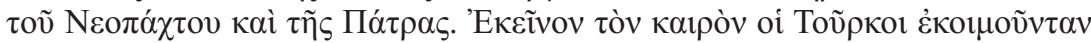

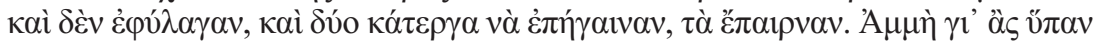

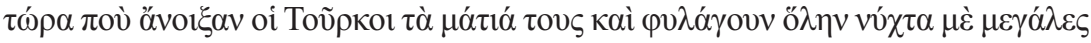

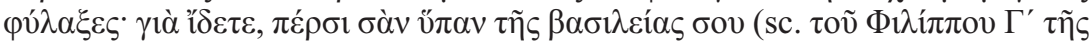

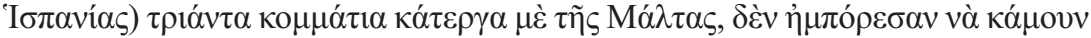

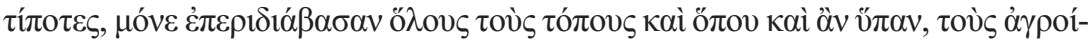

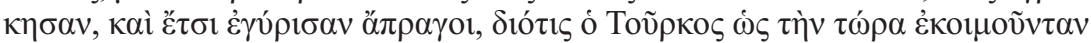

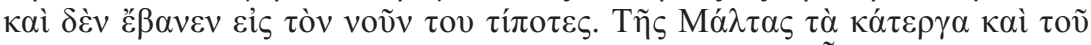

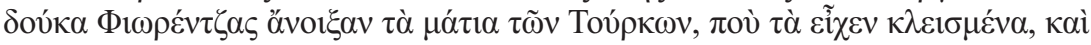

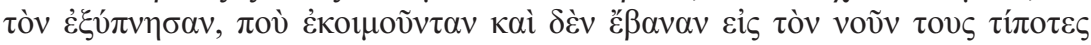
(Floristán, 1988: 175-177).

\section{LA EXPEDICIÓN CONTRA RÍO Y ANTÍRRIO}

El asalto de los caballeros de Malta contra los castillos de Patras (Río) y Lepanto (Antírrio) es conocido desde antiguo'. En el legajo 1487 de la Sección de Estado del Archivo General de Simancas se ha conservado una relación manuscrita de la empresa que edito y gloso a continuación en homenaje de Ángel Martínez Fernández. Soy conciente de que su ámbito geográfico y cronológico dista unas millas y unos siglos del objeto preferido de sus estudios, pero espero, con todo, que acepte esta modesta contribución como munus amicitiae y que su lectura le sirva de solaz en la nueva etapa vital que ahora inicia.

El memorial (f. 97) viajó a Madrid con dos cartas del 19 de mayo del maestre general Alof de Wignacourt (1601-1622) a Felipe III. En una de ellas (f. 93) le pide

${ }^{1}$ Lo cuenta Dal Pozzo (1703: 470-476) con una narración muy cercana a la del memorial que edito, lo que me hace pensar en una fuente común. También coincide en los datos básicos la relación de Thou (1734: 171-173). El breve relato que hace Brogini (2006: 292-293) contiene algunos errores: que la flotilla salió de Malta el 20 de abril (fecha de la toma de las fortalezas), que en ella iban varios miles de soldados y que atacaron los castillos de Petraci y Patras (!).

${ }^{2}$ Nacido en 1547 en una familia francesa noble, el 10 de febrero de 1601 fue elegido $54^{\circ}$ gran maestre de la Orden, puesto que ocupó hasta su muerte en 1622. Ha pasado a la historia por las torres 
que acepte como regalo a unas esclavas que han capturado en los castillos, porque «por ser fortalezas de tanta consideraçión, es justo tenga Vuestra Magestad parte de la empresa». En la otra (f. 96) le pide que escuche la relación que le hará su embajador Gonzalo de Porras ${ }^{3}$ sobre la acción militar y la capacidad de los castillos para albergar una gruesa armada.

En el origen de la expedición estuvo la escasez de trigo que había en Malta tras la mala cosecha recogida en Sicilia, su granero habitual, el verano de 1602. Para remediarla Wignacourt envió cuatro galeones a Bolo (Bó 0 os, Tesalia) y a otros cargaderos de Turquía para hacer alguna presa, pero el mal tiempo hizo que solo pudieran coger 3.500 salmas a algunos caramuzales. De ellas, apenas 2.000 llegaron a La Valeta, porque las restantes les fueron confiscadas en Siracusa y Augusta, adonde una tormenta desvió dos galeones. Ante la necesidad acuciante de trigo el gran maestre decidió atacar los castillos de Río y Antírrio, en los que había abundancia de grano según le habían informado sus espías. Tras estudiar los diseños de las fortalezas y hablar con los informantes, el Consejo de la Orden decidió acometer la empresa. Se aparejaron cuatro galeras, mientras que la quinta quedaba en Malta para las necesidades que pudiera haber. A ellas se añadió un galeón de la Religión y dos de Wignacourt, una tartana y cuatro fragatas, y dos naves arrendadas. Esta pequeña flotilla de $14 \mathrm{embar}-$ caciones se hizo a la mar los días 7 (los navíos redondos, es decir, los galeones) y 9 de abril (las galeras). A 50 millas del puerto de La Valeta toparon con un caramuzal turco cargado de grano que traían de levante unos barcos de Palermo. Los caballeros no dejaron pasar la ocasión y lo remolcaron a puerto. Volvieron a salir y entre los días 16 y 17 llegaron a las islas Equínades, desde las que enviaron caiques y fragatas a explorar el terreno. Por un griego capturado cerca de Lepanto supieron que las plantas de los castillos eran como se les habían presentado en Malta, por lo que decidieron seguir adelante con la empresa. Dividieron la flota en dos mitades, cada una de ellas compuesta por dos galeras, dos fragatas y algunos navíos auxiliares. Los galeones quedaban en la retaguardia esperando la señal de ir a puerto a cargar el botín. Con una fuerza total de 200 caballeros y 800 soldados, cada mitad se dirigió a uno de los castillos, a cuyas puertas se presentaron antes del alba del domingo 20 de abril. Aunque fueron sentidos por los defensores, los sanjuanistas no encontraron dificultades para volar con petardos las puertas de los castillos, colocar las escalas en los muros y entrar en las plazas con relativa facilidad. Solo el agá de Lepanto ofreció cierta resistencia, pero

defensivas costeras que mandó construir y por el acueducto que lleva su nombre, que provee de agua a La Valeta. Durante su gobierno, en 1614 los turcos hicieron un nuevo intento de apoderarse de la isla, pero fueron rechazados. Cf. Whitworth, 1858: II, 339-344.

${ }^{3}$ Nacido en Écija en 1546, fue comendador de Paradinas y de otras encomiendas sanjuanistas, secretario del gran maestre y embajador de la Orden en Roma y Madrid. Recibió el bailiaje de Lora en 1611. Murió en 1613. Su lápida funeraria, situada en la capilla de la Lengua de Castilla, León y Portugal de la concatedral de San Juan en La Valeta, fue publicada por Gil, 1990: 100, no VII. Más datos sobre Porras en Pardo y Manuel de Villena-Suárez de Tangil y de Angulo, 1911: 106. 
al final tuvo que claudicar. Las bajas de los atacantes fueron mínimas, dos caballeros y ocho soldados, sin contar los heridos, más numerosos. Una vez controlados los castillos, los galeones se acercaron a puerto para embarcar el grano. Aunque los turcos intentaban impedir la maniobra desde tierra con sus ataques, la acción conjunta de los cañones de los barcos y de la artillería capturada en los castillos los mantuvo a raya.

Inmediatamente los caballeros se pusieron a buscar el trigo que habían ido a cargar, pero pronto supieron que ese año había gran carestía en la región y que los almacenes, habitualmente llenos, estaban vacíos. Decidieron, por ello, embarcar la artillería de las dos plazas en el galeón de la Orden y en otras dos naves: en total, 76 piezas de mayor o menor calibre. Hicieron, además, 392 esclavos. Después de cuatro días de estancia y de que los castillos resultaran arrasados por un incendio que se declaró por la combustión espontánea de la munición, el jueves $25^{4}$ los asaltantes se embarcaron rumbo a Malta. Conscientes de que el éxito militar no resolvía el problema de la carestía de alimentos que les había llevado a levante, las cuatro galeras, los galeones y la tartana del gran maestre siguieron en dirección sur, mientras el galeón de la Orden y las dos naves que llevaban la artillería capturada ponían rumbo a La Valeta. Las galeras avistaron la isla de Sapientza $(\Sigma \alpha \pi \dot{\varepsilon} v \tau \zeta \alpha)$, frente a la bahía de Modón, al rayar el alba del día 1 de mayo y descubrieron cinco caramuzales fondeados a una milla de la ciudad. Al divisarlos, tres de ellos se pusieron al socaire de la fortaleza, pero los caballeros capturaron los otros dos, cargados con 1.400 salmas de trigo y provistos de 20 pequeñas piezas de artillería. Con esta nueva presa las galeras pusieron proa hacia La Valeta, adonde llegaron el 7 de mayo. Dos galeones, la tartana y las dos fragatas del gran maestre aún siguieron un tiempo surcando aquellos mares para daño del enemigo.

\section{NICOLÁS MARMARÁS}

Su nombre no está en la relación de Wignacourt, pero por otras fuentes sabemos que jugó un papel destacado en la toma de los castillos un caballero llamado

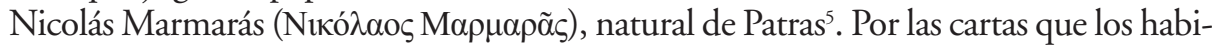
tantes de Maina, en el Peloponeso, enviaron a las autoridades españolas de Sicilia entre 1612 y 1615 para pedir apoyo para un levantamiento antiturco ${ }^{6}$ sabemos que

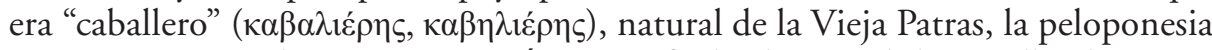

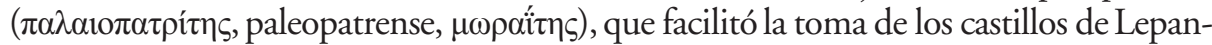

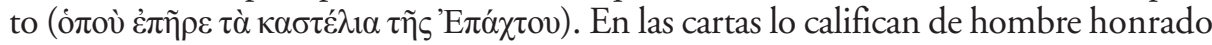

${ }^{4}$ De las dos fechas que da el memorial, el domingo 20 de abril es correcta, mientras que el jueves siguiente fue 24 , no 25 .

${ }^{5}$ Hassiotis (1990: 307-309) dio algunas noticias sobre él, que ahora amplío y preciso.

${ }^{6}$ Láscaris (1957) editó tres, y yo, la documentación completa (Floristán, 1988: 273-299, 348-414). 


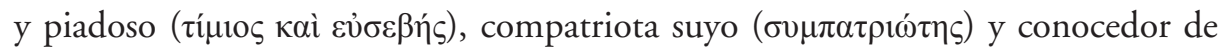

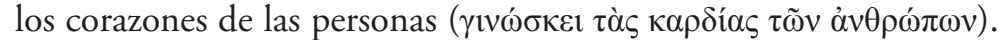

Por una consulta del Consejo de Italia de $1618^{7}$ sabemos que tras su participación en la toma de los castillos, en 1606 actuó como procurador del monasterio de Ntra. Sra. de Portulana (monasterio de los Iberos) del Monte Atos con Josafat Azale ('A $\tau \sigma \alpha \lambda \circ \varsigma$ ), y que por este servicio el rey le concedió una limosna de 1.000 ducados de la partida de tratas de atún, queso y cosas extraordinarias del reino de Sicilia ${ }^{8}$. En Madrid presentó un memorial cuya copia no tiene fecha, pero que probablemente es de septiembre-octubre de ese año?. Al igual que en documentos posteriores, en él se presenta como cerebro de la toma de los castillos de Lepanto y Patras, que había servido para distraer una fuerza de 3.000 espahíes enviados a la guerra de Hungría. Dice que habían capturado 600 turcos y 70 piezas de artillería, y dado libertad a 40 cautivos cristianos. Si las piezas de artillería concuerdan grosso modo con las 76 del memorial de Wignacourt, el número de prisioneros excede con mucho los 392 de este, quizás por el deseo de Marmarás de realzar la importancia de una empresa de la que se presentaba como muñidor. Al dejar los castillos, los sanjuanistas habían capturado dos caramuzales de Janiçarga (¿Yunus agá?) con 2.000 salmas de trigo y otras 25 piezas de artillería, cifras que de nuevo superan ligeramente las del memorial de Wignacourt. Marmarás afirma asimismo que se había traído de la Morea a Malta a su madre, monja basilia, y a otros cinco familiares, y que tenía en el Peloponeso y otras provincias un hermano, dos tíos, dos sobrinos y otros muchos parientes. Por todo ello pidió un sueldo en Nápoles para continuar sus servicios y un viático para ir a Italia, porque había gastado todo su dinero en los diez meses de estancia en España.

El memorial llegó a manos del valido Lerma, que lo envió al Consejo de Estado para su estudio y consulta ${ }^{10}$. Como la respuesta se demorara, Marmarás presentó un segundo memorial ${ }^{11}$. Con él presentó la bula de Wignacourt de concesión del hábito de caballero en premio al valor mostrado en la toma de los castillos, lo que significa que por entonces aún no era caballero, sino simple soldado. El 10 de marzo de 1607 el secretario del Consejo le pidió que declarara si ya había recibido alguna merced, a lo que Marmarás contestó el 15 de forma negativa. Finalmente el Consejo elevó al rey su propuesta de asignación de un entretenimiento mensual de 25 ducados en Sicilia ${ }^{12}$, que el rey sancionó y comunicó al virrey de Sicilia ${ }^{13}$. Durante su estancia en Madrid Marmarás emitió una fe en favor de Jerónimo de Castro y Cabrera

${ }^{7}$ AGS SP994 s.f.: consulta del Consejo de Italia, 6 de junio de 1618.

${ }^{8}$ Sobre esta embajada, cf. Floristán-Valladolid, 2006: 144-147.

${ }^{9}$ AGS E1694 s.f.: memorial de Nicolás Marmarás de 1606, doc. no 2.

${ }^{10}$ AGS E1694 s.f.: billete del duque de Lerma al secretario Villalonga, 8 de octubre de 1606.

${ }^{11}$ AGS E1611 s.f.: memorial de Nicolás Marmarás, 28 de febrero de 1607.

${ }^{12}$ AGS E1611 = E1962 s.f.: consulta del Consejo de Estado, 17 de marzo de 1607.

${ }^{13}$ AGS E1707 s.f.: minuta de carta de Felipe III al virrey de Sicilia, 5 de abril de 1607. 
fechada el 20 de marzo de 1607, es de suponer que como aval de una petición de entretenimiento. En ella dice conocerlo desde cinco años antes (quizás desde la empresa contra Río-Antírrio) y haber coincidido con él de forma especial en dos expediciones, la del marqués de Santa Cruz contra la isla de Longo (Cos) en 1604, y la del adelantado mayor de Castilla y almirante de las galeras de Sicilia, Pedro de Leiva, contra Psili (Anatolia) en 1605. Dice que siempre había servido como caballero aventurero a su costa y que en Longo había resultado herido por una flecha en el muslo izquierdo.

Como ya he dicho, entre 1612 y 1615 Marmarás actuó en Sicilia como agente de los mainotes. Alojó en su casa de Mesina a su embajador, el monje Gabriel Mála-

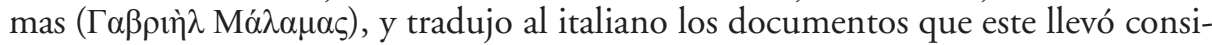
go. Cuando Marmarás había llegado de Madrid a Sicilia en 1607, el virrey duque de Escalona (1607-1610) le había asentado su salario en el castillo de San Salvador de Mesina y asignado labores de trujamán en la correspondencia de levante. Así pasaron cuatro años hasta que en 1611, ante la grave situación de las finanzas de la corona, Felipe III firmó en Aranjuez un decreto de reforma de los salarios de los entretenidos por el que se les quitó una tercia parte de sus sueldos, que quedó para el fisco ${ }^{14}$. Sin embargo, por orden del 2 de octubre de 1612 el virrey Osuna (1611-1616) dispensó a Marmarás de la rebaja, por lo que este siguió cobrando íntegro su sueldo hasta $1614^{15}$. Ese año Osuna lo destinó al servicio en la infantería, que Marmarás no aceptó por ser viejo y estar impedido para seguir una bandera, por no ser la infantería su arma y por ser griego. Como rechazara su nuevo destino, inmediatamente se le aplicó la reforma de su salario, que quedó reducido en un tercio. Pese a ello, siguió sirviendo a la corona a sus expensas, como el nuevo virrey, conde de Lemos (1616-1622), comunicó al rey el 28 de octubre de 1616. El rey contestó ordenando que se le pagara el salario reformado a pesar de su negativa a servir en la infantería ${ }^{16}$.

En mayo de 1617 Lemos dio a Marmarás licencia para viajar a España. En la corte presentó un tercer memorial, en el que pidió se le devolviese el tercio de su salario que se le había detraído ${ }^{17}$. El Consejo de Estado consideró justa su petición y aconsejó al rey la restitución ${ }^{18}$. A la vez Marmarás reclamó al Consejo de Italia los 1.000 ducados que se le habían concedido en 1606 como procurador del monasterio de los Iberos, que aún no había cobrado. Pidió que se pasara esta cantidad de la partida de atún, queso y cosas extraordinarias, a la de espolios y frutos de iglesias sedevacantes,

${ }^{14}$ Copias del decreto, firmado el 23 de mayo de 1611, se han conservado en AGS SP92 s.f. y E2846 s.f. Sobre el decreto, cf. Sandoval, 2013: 399-407.

${ }^{15}$ AGS E1888 f. 382: orden del virrey Osuna a Pedro de Echevarría y Diego Zapata de Cárdenas, veedor y conservador del reino de Sicilia respectivamente. Al dorso del documento se lee: «aviéndosele advertido (sc. al duque de Osuna) que esto es contra la reformación de su Majestad, ordenó que no obstante ello se pusiese en execución».

${ }^{16}$ AGS E1733 s.f.: minuta de carta de Felipe III al conde de Lemos, 10 de enero de 1617.

${ }^{17}$ AGS E1652 s.f.: memorial de Nicolás Marmarás, 30 de abril de 1618.

${ }^{18}$ AGS E1989 s.f. = E1652 s.f.: consulta del Consejo de Estado, 5 u 8 de mayo de 1618. 
al parecer, de cobranza más segura. Así se lo recomendó el Consejo de Italia al rey ${ }^{19}$. Ignoro la decisión final que se tomó en este asunto, pero sí tengo noticia sobre la petición hecha al Consejo de Estado. En cumplimiento de la consulta de este, el rey ordenó a Lemos que le repusiera el sueldo íntegro de 25 ducados, que le librara las cantidades que había dejado de cobrar por la reforma y que en el futuro se le pagara en el castillo de San Salvador, como se había hecho antes ${ }^{20}$. Esta es la última noticia que he podido localizar sobre Marmarás, que desde entonces entra en la penumbra de la Historia.

\section{REFERENCIAS BIBLIOGRÁFICAS}

BARTL, P. (1974): Der Westbalkan zwischen spanischer Monarchie und osmanischem Reich, Otto Harrassowitz, Wiesbaden.

BRogini, A. (2006): Malte, frontière de la chrétienté (1530-1670), Roma: École française de Rome.

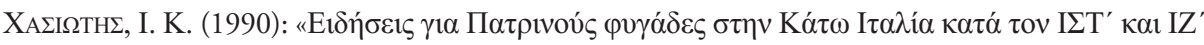

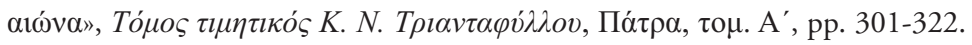

Dal Pozzo, B. (1703): Historia della sacra Religione militare di S. Giovanni Gerosolimitano detta di Malta, del signor commendator fr. Bartolameo dal Pozzo veronese, cavalier della medesima, Parte prima, che proseguisce quella di Giacomo Bosio dall'anno 1571 fin'al 1636, per Giovanni Berno, in Verona.

Floristán, J. M. (1988): Fuentes para la política oriental de los Austrias. La documentación griega del Archivo de Simancas, Universidad, León.

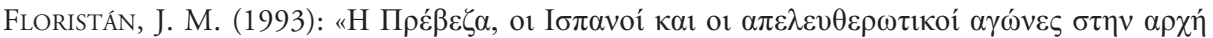

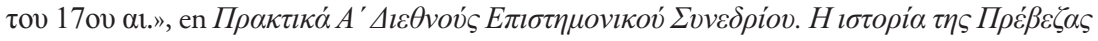

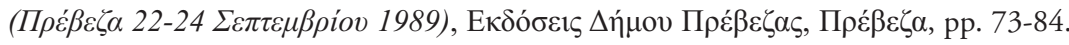

FLORISTÁN, J. M. (1998): «Los prolegómenos de la tregua hispano-turca de 1578. Historia de una negociación», Südost-Forschungen 57: 37-72.

FloristÁn, J. M. (2017): «Los contactos de Chimarra con Roma y España en la segunda mitad del s. XVI y primeras décadas del s. XVII», Erytheia 38: 139-182.

Floristán, J. M. - VAlladolid, A. (2006): «Mendicantes atonitas en la Corte de Felipe III (1602-1620)», Erytheia 27: 137-165.

FUNES, Juan Agustín DE (1639): Coronica de la ilustríssima milicia y sagrada religión de San Iuan Bautista de Ierusalem [...] Segunda parte por fray don Iuan Agustín de Funes, Pedro Verges, Çaragoça.

GIL, L. (1990): «Epitafios sanjuanitas hispano-melitenses», Boletín de la Real Academia de Buenas Letras de Barcelona 42: 81-115.

${ }^{19}$ AGS SP994 s.f.: consulta del Consejo de Italia, 6 de junio de 1618.

${ }^{20}$ AGS E1740 s.f.: minuta de carta de Felipe III al conde de Lemos, 26 de junio de 1618. 


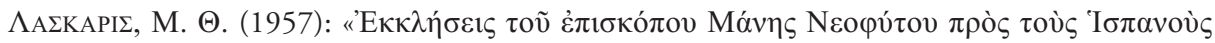

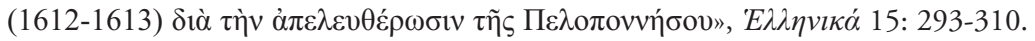

Pardo y Manuel de Villena, A. - SuÁrez de Tangil y de Angulo, F. (1911): Índice de pruebas de los caballeros que han vestido el hábito de San Juan de Jerusalén (Orden de Malta) en el gran priorato de Castilla y León desde el año 1514 hasta la fecha, Librería de F. Beltrán, Madrid.

SANDOVAL, V. (2013): Manera de galardón. Merced pecuniaria y extranjería en el siglo XVII, Universidad de Murcia [Tesis doctoral] [https://digitum.um.es/digitum/bitstream/10201/30285/1/ TESIS\%20SANDOVAL\%20PARRA.pdf].

THOU, Jacques-Auguste DE (1734): Histoire universelle de Jacque-Auguste de Thou, depuis 1543 jusquien 1607, traduite sur l'édition latine de Londres, t. 14 [1601-1607].

VERTOT, René-Aubert (1772): Histoire des chevaliers hospitaliers de S. Jean de Jérusalem, nouvelle édition augmentée, chez Duran Nevend, a Paris.

Whitworth Porter, M. (1858): History of the Knights of Malta or the Order of the Hospital of St. John of Jerusalem, 2 vols., Longman, Brown, Green, Longmans \& Roberts, London.

\section{DOCUMENTOS}

\section{AGS E1487 f. 97}

Breve relación de la pressa y expugnación de los dos castillos puestos I a la boca del golfo de Lepanto y Petrache, hecha de las fuerças de la Sacra I Religión Hierosolimitana y del illustrísimo gran maestre della, domingo por la mañana, a I 20 de abril $1603 . \mid$

No haviendo en el presente año la Religión podido haver de Sicilia su I acostumbrada provisión de trigo por la falta que en aquel reino a havido,l determinó el illustrísimo gran maestre, temiendo algún gran trabajo, embiar al Bolo | y a otros cargadores del turco quatro galeones armados con designio y espelrança de hazer buena presa dél. Pero por causa de los malos tiempos no I pudieron los dichos vageles tomar más de 3.500 salmas cargadas sobre I algunos caramuzalíes, de las quales vinieron a este puerto 2.000 , porque I los vageles que traýan las demás fueron a Çarag oça ${ }^{21}$ y Augusta forçados del I tiempo, y aquellas çiudades se aprovecharon dél por padezer la misma | falta. Visto su señoría ill ustrísima que esta no era provisión sufficiente para redelmir nuestra necesidad y que el prior de Navarra don Bernardo de Ezpeleta ${ }^{22}$, a I quien se havía embiado a Palermo a representarla a su excelencia y a los juelçes de aquel real patrimonio, escrevía le havían excluýdo de su delmanda, no por no dessear provehernos, sino por no serles possible el hazello, I compadeciéndose de la neçesidad de sus súbditos y vassallos, como padre y I señor de todos se determinó de emprender los castillos

${ }^{21}$ Siracusa.

${ }^{22}$ Bernardo de Ezpeleta, de linaje originario de la Navarra de Ultrapuertos, fue gran prior de Navarra de la Orden de San Juan, comendador del gran maestre, capitán general de la armada de Malta y embajador del gran maestre en varias misiones. Murió en 1617 con 69 años. L. Gil editó y tradujo su epitafio (1990: 110, no XVIII). 
de Lepanto y Petrache I por tener relación de personas dignas de fe con quien tenía muchos melsses a intelligencia, que tomándolos se hallaría en ellos cantidad de I trigo. Y assí después de haverlo encomendado muy de veras a Dios Nuestro I Señor, lo propuso su señoría illustrísima al Consejo, donde se resolbió que los señores I gran baylío de Alemaña Arbogasto Abandelao ${ }^{23}$ y el gran canciller Hernando I Ruiz de Corral ${ }^{24}$ y fr. Raymundo de Gozon Melac, prior de Tolosa ${ }^{25}$, y fr. I Centorio Cañolo, prior de Santa Eufemia ${ }^{26}$, y fr. Antonio Canbiano, almiralle I y general de las galeras ${ }^{27}$, y fr. Jaques de Blot Viviers, baylío de León ${ }^{28},\left.\right|^{\mathfrak{f} 2}$ a quien se hizo general de tierra en presencia de monseñor ill ustrísimo, tratassen I maduramente este negocio. Los quales después de havello considerado y milrado y conferido con las espías y visto el designio de los dichos castillos, relsolbieron se hiziesse la empressa, y habiendo dado de su resolución parte I al Consejo, fueron de su mismo parecer, y assí se hizieron las instrucciones I y nombraron officiales al comendador Juan Luis Beufort ${ }^{29}$, de la lengua de Alberlnia ${ }^{30}$, para que desenbarcase con el estandarte, y sargentos mayores, de I Italia al comendador Señorín Gatinara $^{31}$, capitán de la galera San Phellippe, y de I Francia al cavallero Potonbile ${ }^{32}$, y de España a don Juan de Salazar ${ }^{33}$. Y I luego mandaron poner en orden quatro galeras de la Religión bien reforlçadas porque pareció conbiniente quedasse la una en la isla para lo que

${ }^{23}$ Arbogast von Andlau / Andlaw (1550-1612) fue comendador de Tobel (Suiza), Feldkirch (Austria) y Friburgo (Suiza). Entre 1598 y 1599 fue bailío de Brandenburgo y posteriormente de Dacia (hasta 1601). En 1601 fue nombrado gran bailío y en 1612 gran prior de Alemania. El linaje nobiliario Andlau era originario de Alsacia. En la actualidad Andlau es una comunidad del departamento francés del Bajo Rin. Cf. Kindler von Knobloch, Oberbadisches Geschlechterbuch, Heidelberg: Carl Winter's Universitätsbuchhandlung, 1894: vol. 1, pp. 13-14, s.v. «von Andlau».

${ }^{24}$ Fernán Ruiz de Corral fue gobernador de la isla de Malta, castellano de la fortaleza de San Ángel (1586), bailío de Negroponte (1597) y de las Nueve Villas de Campos (1606), gran canciller de Malta (1598) y general de las galeras de la Religión (1598). Se destacó en la defensa de la isla frente a los turcos en 1565. Cf. Pardo y Manuel de Villena-Suárez de Tangil y de Angulo, 1911: 122.

${ }^{25}$ Raymond de Gozon Melac fue gran prior de Tolosa de la Orden de San Juan entre 1597 y 1610. Sobre la familia Gozon, cf. el Dictionnaire généalogique, héraldique, historique et chronologique, t. V, Paris: chez Duchesne libraire, M.DCC.LXI, pp. 241-242. Sobre el priorato tolosano, cf. M. A. du Bourg, Histoire du grand-prieuré de Toulouse, Toulouse: Louis Sistac et J. Boubée, 1883.

${ }^{26}$ Fr. Centorio Cagnoli (Gian Angelo Centorio Cagnoli) fue prior de la bailía de Sant'Eufemia Lameza, localidad actualmente incorporada en el municipio de Lamezia Terme (provincia de Catanzaro, Calabria). Cf. C. Angelino Giorzet, Lozzolo e i signori del Castello Loceno, Lozzolo 2014: 72, n. 128.

${ }^{27}$ Encuentro un fray Ascanio (no Antonio) Cambiano, caballero de la Orden de la lengua de Italia, en las fuentes siguientes: La verdadera relación de todo lo que el anno de M.D.LXV ha succedido en la isla de Malta [...] recogida por Francisco Balbi de Correggio, Barcelona: Pedro Reiguer, 1568, f. 110v; Funes 1639: 602.

${ }^{28}$ Jacques de Blot Viviers fue capitán general de las galeras de Malta.

${ }^{29}$ Jean Louis Beaufort era hermano de Antoine Beaufort, barón de Montailleur (Saboya).

${ }^{30}$ Auvernia.

${ }^{31}$ Signorin Gattinara, bailío de Santa Eufemia.

${ }^{32}$ René Rivery-Potonville, admitido como caballero en 1583. Cf. Vertot 1772: vol. 7, p. 221222 y Catalogue général et alfabétique des familles nobles de France admises dans l'Ordre de Malte, Paris 1815 , p. 87.

${ }_{33}$ Sobre Juan de Salazar, natural de Esquivias, cf. Pardo y Manuel de Villena-Suárez de Tangil y de Angulo, 1911: 130-131. 
I se podía offreçer, y un galeón de la Religión y dos del gran maestre y | una tartana y quatro fragatas, y se nolejaron ${ }^{34}$ dos naves que se hallaron I en este puerto, una de 2.300 salmas y otra de 1.000. Toda esta armalda estuvo en orden a los 7 de abril y aquel día partieron los vajeles reldondos y a los 9 hizieron lo mismo las galeras, sobre las quales, estanldo a punto de partir, fue su señoría illustrísima a reconoçer y hazer reseña I de toda la gente y armamento y dio las últimas órdenes oportunas y neçelsarias con que salieron deste puerto en seguimiento de su viaje, y por buen prinlcipio fue Nuestro Señor servido que dichas galeras hallassen a 50 millas I desta isla un caramuzalí turquesco cargado de trigo preso en levante I de vageles armados en Palermo. Y habiéndolo conducido a la boca deste I puerto, sin detenerse un punto tornaron a su viaje, el qual fue assí próspero,I que a los 16 llegaron a las islas Cuchillaras ${ }^{35}$, adonde el siguiente día I llegaron sin ser descubiertos todos los otros vageles. Y de allí se embiaron I dibersas vezes cayques y fragatas a tomar lengua con el capitán Vinlziguerra ${ }^{36}$ y con el cavallero Claret provenzal ${ }^{37}$, el qual trajo un griego I que tomó junto el castillo de Lepanto. Y hallándole conforme $\|^{\mathrm{f3}}$ con lo que se havía reconocido de las relaciones y designios que se I vieron en Malta, los dos generales con su Consejo resolbieron de seguir I la empresa, y assí hizieron enbarcar sobre las galeras, tartanas y fragaltas, y sobre tres barcas de griegos que hallaron cargadas de trigo, tolda la gente que estava señalada para las empresas de tierra, el núlmero de la qual fue 200 cavalleros y cerca de 800 soldados que I se dividieron en dos partes: la una de ellas con el baylío de León solbre las galeras capitana y San Juan, dos fragatas y varcas se fue I a la empresa del castillo de Petracho puesto en la parte de la Morea, y el I comendador Gatinara, con las galeras patrona y San Phellipe, tartana y dos I fragatas fue a la expugnación del otro castillo de Lepanto, puesto a la parte de la I Greçia. Y se desenbarcaron, assí la gente de la una parte como de la otra,l a ora y en el lugar que, antes del amaneçer a los 20 de abril, se I hallaron a las puertas de los castillos. Y aunque fueron sentidos y descubilertos de los enemigos y que dentro se pusiessen en armas, con todo esto, con I grandísimo ánimo cassi en un mismo tiempo fueron puestos los petarldos a las puertas del uno y del otro, y assí mismo fueron puestas las I escalas, de suerte que con el buen effeto que hizieron los petardos, no I obstante que en el castillo de Petrache fuesse menester poner dos por I haver dos puertas, entraron los nuestros felicísimamente con tal orden, que a los I turcos, los quales de las murallas y de algunas torres tiravan arcabuzalços y otras armas, les fue forçoso retirarse huyendo, y algunos haziénldose fuertes en las torres y retirados dentro dichos castillos, en particullar en el de Lepanto, adonde el propio agá con otros muchos que I le siguieron estuvieron obstinados un gran rato conbatiendo sin quelrerse rendir. Al fin, después de haverlos cassi muerto a todos, se abanldonaron del todo y los nuestros quedaron patrones, haviendo muerto los calballeros fr. Alesandro Martinengo y Pussiens, provenzal, y 8 soldados, || ${ }^{\text {f.4 }}$ y otros muchos heridos. Y en esto llegaron los galeones y naves y dieron I

${ }^{34}$ Del it. noleggiare, 'arrendar'.

${ }^{35}$ Del it. Curzolari, nombre con el que se conocían las islas Equínades, en la desembocadura del río Aqueloo, al E de Ítaca.

${ }^{36}$ Vinciguerra.

${ }^{37}$ En la Histoire de Vertot (1772) encuentro dos Claret por estas fechas: Nicolas-Edouard de Claret Saint-Felix en 1584 (p. 26) y Richard de Nini-Claret en 1586 (p. 64), ambos, de la lengua de Provenza. Thou escribe De Claire por Claret. 
fondo entre los dos castillos, de manera que de ninguna parte se podía I impedir el fin desta empresa, porque si bien venía cavallería continualmente y infantería enemiga de la parte de tierra, creçiendo siempre I más para cobrar los dichos castillos y impedir la embarcación, la hazían I estar lejos no solamente la artillería de nuestros vageles, pero la suya propia I que estava en poder de los nuestros, y también con algunas esquadras que de quando I en quando salían de los castillos para impedir que los enemigos no se alolxassen en ciertas cassas y jardines que havía allí cerca. Los generales hilcieron diligencia en entender y saber dónde pudiessen haber trigo, y les dijeron I y confirmaron, assí turcos como griegos que ay en aquel país, que padezen I extraordinaria carestía, adonde todos los magazenes que de ordinario | solían estar llenos, se hallavan vazíos, y que algunos turcos de la guarlnición de dichos castillos estavan en campaña a hazer traer para su prolvisión. Y assí resolbieron enbarcar toda la artillería enemiga, de I la qual los dichos castillos estavan reforçadísimamente proveýdos, sobre el I galeón de la Religión y las naves: halláronse en todos 76 piezas de I artillería, entre las quales ay 12 de vatir, 2 grandes cañones, 7 cañolnes pedreros, 5 medias culebrinas, 6 bastardos y 8 medios cañones, l y las demás piezas pequeñas de campaña, pero todas de cuchara. Y siguilendo con gran orden, assí la embarcación de la artillería como la de I 392 esclavos que los nuestros tomaron en los dichos castillos, después I de haver estado patrones dellos quatro días, siempre con la vitoriosas I insignias de San Juan Baptista arboladas, abrasados y fracasados los I edificios y que el uno y otro lugar la munición tomó fuego sin salberse cómo con grandísimo ruydo y espanto, el jueves a 25 se hallalron los nuestros embarcados y, no contentos deste suçesso, pareçiéndoles que I si venían sin trigo, no era cumplido su designio y que a estas islas se II f.5 les crecería mayor trabajo del que por falta dél tenían, determinaron | de passar adelante las galeras con los dos galeones y tartana del gran maestre I a buscarle, y el dicho galeón de la Religión con dos naves cargadas con I toda la presa se vinieron la buelta de Malta.I

Después, a los 7 de mayo an llegado por la gratia de Nuestro Señor las I quatro galeras a este puerto, las quales an traýdo dos caramuzalíes carlgados de trigo que, según se juzga, no serán menos de 1.400 salmas, I sobre los quales se an hallado 20 piezas pequeñas de artillería.l Refieren dichas galeras que después que se apartaron de los vajeles que I an traýdo aquí los esclavos y artillería, tiraron la buelta de la Sapilencia, adonde llegaron el primero de mayo al hazer del día, y de allí embialron un cayco a reconocer si devaxo de Modón había vageles, y refirienldo que havían descubierto cinco caramuzalíes çerca de una milla de la I fortaleza, se fueron azia allá sin perder un punto de tiempo, y habienldo sido dellos descubiertos, hizieron grandísima diligencia en retirarse devajo I la dicha fortaleza, que atendía a disparar artillería hazia las galeras, l las quales, mientras se pusieron tres de los caramuzalíes en seguro, tomalron los otros dos que no fueron tan diligentes en retirarse debajo la I dicha fortaleza, sin aver podido tomar ningún esclavo por averse toldos los turcos salbado en tierra, de suerte que el socorro de dicho I trigo, por hallarse tan cerca de la cosecha, será de mucha ayuda a la I necesidad en que estamos, de que se an dado infinitas gratias a Dios I Nuestro Señor, del qual esperamos que los grandes galeones, tartana y dos fralgatas del illustrísimo gran maestre que an quedado en aquellos mares I para daño de los infieles nos an de hazer sentir bien presto nueva I de alguna otra buena empresa.I

\section{AGS E1694 s.f.}

El cavallero fray Nicolás Mármara de la orden de san Juan dize que haviendo I hecho la entrepresa de los castillos de Lepanto y Petraqui del turco con las 4 galeras I de Malta y preso seiscientos turcos y settenta pieças de artillería de bronce y dado I libertad a 40 xp.ianos cautibos, y demás desto hizo grandíssimo servicio al emperador,l por causa que los 
tres mil cavallos que embiava el gran turco en Ungría se detulbieron para yr, como fueron, a defender las dichas dos fortaleças y impedir la I dicha entrepresa, la qual acabada, saliendo afuera con las galeras, el supplicante I fue causa que se prendiessen dos caramusales cargados con dos mil salmas de trigo I que yvan en levante, y con ellos otras 25 pieças de artillería que eran del janiçarga I de Costantinopla, lo que fue y es gran soccorro a la Religión y a todos los de la isla I vassallos de Vuestra Majestad, mayormente por este año, no podiéndole esperar de Sicilia por I la poca cosecha que ha havido, como parece muy cumplidamente por el privilegio del I Gran Maestre. Y teniendo correspondencia, conocimiento y experiencia para I poder hazer otros servicios importantes y de mucha calidad, ha venido a los reales pies I de Vuestra Majestad a offrecerse en su real servicio, como de un rey y corona que es amparo y I defensa de toda la xp.iandad, y le supplica que, atento su calidad y servicios hechos I a dicha su Religión, los quales vuestra Majestad siempre ha tenido por propios, siendo protector I della, y los que espera de hazer con el favor de Nuestro Señor por la grande inteligencia I que en todo levante tiene $-y$ de los effectos de la dicha entrepresa lo ha mostrado-, de donde I ha traýdo a su madre, monja de san Basilio, y otros cinco parientes que hoy día están I en Malta, y en la Morea y otras provincias tiene un hermano, dos tíos, dos I sobrinos y otros muchos parientes y deudos suyos, se sirva usar con él de su I real grandeça, mandando hazerle merced de uno honrrado entretenimiento cerca la perlsona del virrey de Nápoles y de una ayuda de costa digna de un monarca I tan grande, que ha más de 10 meses que está en la corte con dos criados suyos I gastando lo que tenía, como espera de la poderosa y real mano de Vuestra Majestad.I

Al rey nuestro señor,I del I cavaller fray Nicolás Mármara de I la orden de san Juan Hierosolimitano.I 
